\title{
Interactive comment on "Size-resolved exposure risk of persistent free radicals (PFRs) in atmospheric aerosols and their potential sources" by Qingcai Chen et al.
}

Qingcai Chen et al.

dryanlinzhang@outlook.com

Received and published: 16 August 2020

please find the responses in the supplement

Please also note the supplement to this comment:

https://acp.copernicus.org/preprints/acp-2020-141/acp-2020-141-AC1-supplement.pdf 